\title{
Vocational Teacher Training Process in Professional Education for Principle of Router
}

\author{
Di Miao", a, Shixin $\mathrm{Li}^{1, b}$, Xin Su${ }^{2, c}$, Linglin $\mathrm{Li}^{1, \mathrm{~d}}$ \\ ${ }^{1}$ School of Electronic Engineering, Tianjin University of Technology and Education, Tianjin 30000, \\ China; \\ ${ }^{2}$ Chengxi Electric Power Supply Branch, Tianjin Electric Power Co., Ltd, Tianjin 300192, China. \\ a09111042@bjtu.edu.cn, bli_shixin@sina.com, cdxczh007@163.com, d453094036@qq.com
}

\begin{abstract}
The problems of vocational teacher training process in professional education has rigid teaching mode and single educational means. With the development of router technology, the curriculum of the principle of routers is the core course for information majors. In this paper, we show the vocational teacher training process for principle of router. We take the method of teaching plan highlights double skills training and double certification system for performance assessment, in order to improve the quality of teaching. And then we give an example of new part of teaching in principle of router, which is Mini-NDN Platform, to provide a mechanism for improvement teaching quality.
\end{abstract}

Keywords: Vocational teacher training, network, professional education, double-certificate, principle of router.

\section{Introduction}

With the development of router technology, the curriculum of the principle of routers is the core course for information majors. This course involves a lot of related knowledge of data communication technology and computer technology. It is the leading course of any network related courses [1], and is also an essential course for students to understand the working mechanism of computer network. How to introduce the new computer network technology in this course, combine the actual networking case and comprehensive training, strengthen the students' learning enthusiasm and improve the practical ability, let the students grasp the basic knowledge of the computer network [2], and have the ability to apply the computer network engineering to the information class teacher to carry out the computer.

In this paper, we show the vocational teacher training process for principle of router [3]. It is hoped that the employment competitiveness of higher vocational students can be greatly improved and the purpose of improving students' employability skills can be achieved. In order to cultivate high quality skilled talents, students can grasp their basic principles and operational skills through learning the course of the principle of router, cultivate the students' ability to analyze and solve problems[4], and make full use of the flexible and diverse teaching methods, such as heuristic, discussion and research.

\section{Integration of Teaching Content}

The employment oriented vocational education should first solve the teaching content to meet the teaching requirements. Generally speaking, the course content can be divided into two major categories: one is "declarative knowledge" involving facts, concepts, understanding, principles, and "process knowledge" involving experience and strategy. Taking the working process as a frame of reference, integrating declarative knowledge with procedural knowledge, integrating theoretical knowledge with practical knowledge. Obviously, in the limited course of class [5], it should be based on process knowledge and declarative knowledge, that is, the acquisition of practical experience and strategy, and the understanding of the concept and principle of moderate enough. 


\section{Training of Vocational Teachers}

The training objects of vocational colleges are applied talents with high skills. Vocational education should adhere to the "student oriented" and "employment oriented". Combined with the training objectives and characteristics of higher vocational students, emphasizing practical training links, we can improve students' practical ability through some auxiliary means. For example, a part of the professional technicians and managers who understand both theory and practice, experienced and skilled are employed as part-time teachers from enterprises and institutions to form a high level and high quality "double teacher" Teacher Based on full-time teachers.

On the basis of this course, the following training can give full play to the role of the training base outside the school and the part-time teachers of the enterprise, let the students contact the enterprise directly, and make the students understand the actual working environment of the enterprise, the project implementation process and the latest technology and dynamics of the current network. So that students can form a direct understanding of their jobs and adapt to the actual job requirements as soon as possible. Obtaining professional qualification certification can improve students' employment competitiveness. The college organization training encourages students to take part in CCNA, CCNP, CNE, HCSE and other qualification certification examinations, which lays the foundation for the students to apply for employment and to better adapt to the social needs. Qualification certification the "double certificate system" actively implements the system of vocational qualification certificate in vocational education teachers, and carries out both the certificate and the professional qualification certificate. It is to make the training of Higher Vocational Talents in line with the employment market, improve the professional quality of higher vocational students and the ability to compete in the employment, and cultivate the social development and market demand. The needs of adaptable talents.

\subsection{Teaching Plan Highlights Double Skills Training}

Double skills [6], namely professional skills and education and teaching skills, are the inevitable requirements of the technical nature of vocational education, and are the comprehensive performance of the teaching quality of vocational technical teachers. In order to highlight the dual-skill training, our school has specially formulated a professional skill training system and a teacher skill training system when formulating the teaching plan. In the construction of professional skills training system, the main professional courses of 39 majors in the whole school are based on the close combination with theoretical teaching. According to the professional characteristics, 10 to 15 major and representative ones are selected from a variety of professional skills. Skilled skills projects are required to test skills and develop specific training programs and assessment criteria. In the training of teacher training skills, we have strengthened the teacher-friendly curriculum and established courses such as Subject Teaching Methodology, Teacher Training Skills, Microteaching, and Moral Education Teacher's Guide. The tasks, tasks and measures have been clearly defined, and students' skills training cards have been established. They have been divided into different categories of training and assessments, and require that Putonghua, three-character words, teaching work skills, and class teacher work skills are up to the level of qualified teachers. At the same time, students are encouraged to participate in the examination of teacher qualifications and develop genuine vocational education technicians.

In order to avoid the contradiction between teacher training and embedded training, to better reflect the characteristics of vocational teacher training, the teaching method of "demonstration teaching" was proposed to allow students to experience different teaching styles.

\subsection{Double Certification System for Performance Assessment}

The implementation of the double-certificate[7] system is a direct result of the dual-skill training and is one of the important symbols of the scientific and standardized vocational education. Double certificates are academic certificates (including diplomas and degree certificates) and professional and technical grade certificates. Academic certificates show that graduates have a considerable level of academic qualifications, and professional and technical grade certificates reflect the professional skills of graduates. The "dual-certificate" system developed by embedded teachers means that 
students are required to obtain academic certificates in all courses prescribed in the teaching plan, and they must also pass the skill level certification established by the college on the basis of preliminary grasp of embedded operating skills.

\section{Example for Mini-NDN Platfarm}

For example, we show the new technology of NDN network for the course of principle of router. We want to show the student the number of nodes and links that Mini-Nan can instantiate and run, analyze the scalability. Therefore, two representative topologies are selected: (1) full mesh, and (2) linear (connected nodes in a simple linear fashion). These topologies are selected because they represent two connection restrictions - any other topology will have a connection level in this range. Tables 1 and 2 show the number of instantiated NDN nodes, the memory used by Mini-NDNx only, the total memory used by the ccnd daemon instance running on each node, the total amount of memory (Mini-NDNx+ccnd) links and each The setting time of the scenes. Note that the largest portion of memory usage comes from the ccnd daemon and this memory usage grows linearly with the number of nodes. From experiments, the setup time is closely related to the number of instance links, and it becomes a limiting factor ( $>10 \mathrm{~min}$ ) for a full mesh topology of 128 nodes. When looking at the linear topology, the memory reached a bottleneck after 1,500 nodes.As is shown in Table 1 and Table 2.

Table 1. Linear Topological Parameters

\begin{tabular}{cccccc}
\hline Node & NDN memory & Ccnd memory & Total memory & Connection & Establishing time \\
\hline 4 & 15.0 & 7.2 & 22.2 & 3 & $<1$ \\
64 & 15.7 & 113.8 & 129.5 & 63 & 6 \\
512 & 21.6 & 918.5 & 940.1 & 511 & 95 \\
\hline
\end{tabular}

Table 2. Mesh topology Parameters

\begin{tabular}{cccccc}
\hline Node & NDN memory & Ccnd memory & Total memory & Connection & Establishing time \\
\hline 4 & 15.0 & 7.2 & 22.2 & 3 & $<1$ \\
64 & 15.7 & 113.8 & 129.5 & 63 & 6 \\
512 & 21.6 & 918.5 & 940.1 & 511 & 95 \\
\hline
\end{tabular}

And for another example, we show IP address as Fig.1

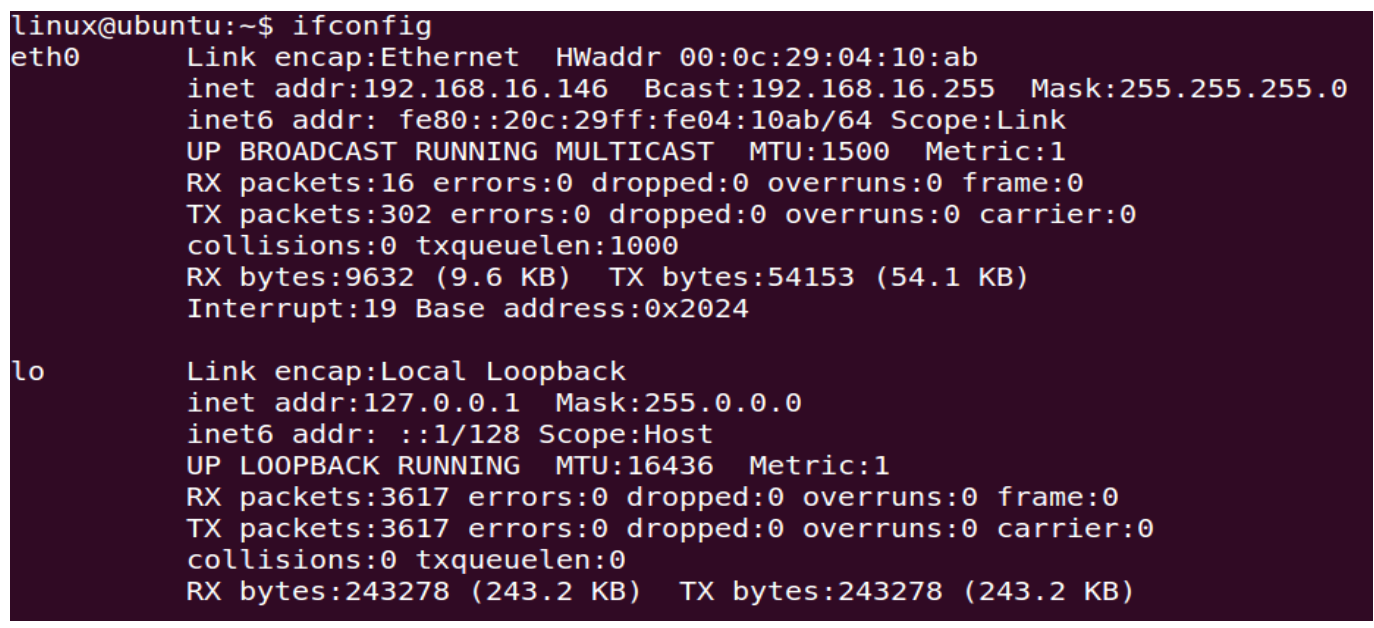

Fig 1. IP address

\section{Summary}

Education should adhere to the concept of "taking students as the base", guided by the theory of education, in order to stimulate students' interest in learning, effectively mobilize the students' 
enthusiasm for learning, promote the students to think actively and stimulate their potential. By carrying out the cooperation of school and enterprise, the "double certificate" system will be carried out to shorten the students' position. It is hoped that the employment competitiveness of higher vocational students can be greatly improved and the purpose of improving students' employability skills can be achieved. In order to cultivate high quality skilled talents, students can grasp their basic principles and operational skills through learning the course of the principle of router, cultivate the students' ability to analyze and solve problems, and make full use of the flexible and diverse teaching methods, such as heuristic, discussion and research.

With the development of router technology, the curriculum of the principle of routers is the core course for information majors. In this paper, we show the vocational teacher training process for principle of router. We take the method of teaching plan highlights double skills training and double certification system for performance assessment, in order to improve the quality of teaching.

\section{References}

[1]. GAO S, Yuan X. Comparison and Enlightenment of Professional Teacher Training in Vocational Schools in China and Germany [J]. Journal of National Academy of Education Administration, 2017.

[2]. Shen W, Zhou Z. On Construction Mechanism of the Vocational Education Teachers' Training Group [J]. Journal of Chongqing Normal University, 2017.

[3]. Zhang B. Construction of Collaborative Innovation Teacher Training Base for Meld Specialty in Higher Vocational College [J]. Education Teaching Forum, 2017.

[4]. De Mendon E D F M, Gomez Galan J. Professional Practice in Higher Education: A Case Study in Faculty Training and Development in Brazil [J]. Social Science Electronic Publishing, 2018, 2(2):51-64.

[5]. Price N A, Cabo Verde C E C. Technical-Vocational Education and Training for Business Process Management: Challenges and Potential [J]. Social Science Electronic Publishing, 2017.

[6]. Diaz L A, Delgado S C, Esteban P, et al. Digital training in intercultural education for teacher training: analysis of an innovative experience [J]. International Journal of Continuing Engineering Education and Life-Long Learning, 2018, 28(1):1.

[7]. Seller M, Blitzer P, Jansen A, et al. Process is king: Evaluating the performance of technologymediated learning in vocational software training $[\mathrm{J}]$. Journal of Information Technology, 2017(2):1-21. 